\title{
The analysis of the external factors influence on the efficiency of the absorption heat pumps inclusion in the scheme of a two-stage line installation of a STP
}

\author{
Dmitriy S. Luzhkovoy ${ }^{1}$, Olga Yu. Romashova ${ }^{1, *}$, Marina A. Vagner ${ }^{1}$, Aleksandr A. \\ Tubolev ${ }^{1}$, Juri $V$. Kobenko ${ }^{1}$, and Elena $S$. Riabova ${ }^{2}$ \\ ${ }^{1}$ National Research Tomsk Polytechnic University, 634050 Tomsk, Russia \\ ${ }^{2}$ Samara University, 443086 Samara, Russia
}

\begin{abstract}
The article deals with a comparative analysis of the efficiency of a two-stage line installation in a heating turbine before and after the inclusion of absorption heat pumps into its scheme with a decrease in the outside air temperature. The research shows the dependence of the efficiency of the line installation on its heat load while using AHP in its scheme, as well as on the heat conversion factor of the absorption heat pumps.
\end{abstract}

\section{Introduction}

Two-stage heating of the delivery water at the CHP in comparison with the one-stage heating allows to increase the generation of electricity by heating consumption. Modern heating turbines exclude the possibility of maintaining an equal heating distribution of the delivery water within the entire heating period, which leads to a decrease of the efficiency of the heat-producing power generation [1-3].

It is known that the heating distribution substantially depends on outside air temperature [4]. When turbines are operating in the heating mode, the water heating in the lower line heater with a decrease in the outside air temperature increases with a corresponding decrease in the upper heater. Other things being equal, unevenness of the line heating increases with a decrease in the flow of the delivery water and an increase in its temperature in the return line [5].

The calculations of the operating modes of a two-stage line installation in a turbine of the T-110-130 type in Tomsk climatic conditions (the minimum design outside air temperature for heating $\mathrm{t}_{\text {out.tem. }} \mathrm{d}^{\mathrm{a}}=-40^{\circ} \mathrm{C}$ ) for the heating system graph $150 / 70$ and the extraction factor $\alpha_{\mathrm{CHP}}=0.6$ show that the heating proportion in the lower stage during the turbine operation in the heating mode with the nominal heat load varies from a value, that is close to $50 \%$ at the temperature of switching the peak water-heating boilers, to $80 \%$ at $\mathrm{t}_{\text {out.tem. }}$. [4].

\footnotetext{
Corresponding author: roma@tpu.ru
} 
This research shows the calculation analysis of the use of an absorption heat pump (AHP) to equalize the stage heating of the delivery water with a decrease in the outside air temperature. The calculations were carried out in two stages. At the first stage, the efficiency of the line installation with AHP was analyzed with a change in the heat load $\mathrm{q}=$ $\mathrm{Q}_{1 . \text { inst. }}, \mathrm{Q}_{1 . \text { inst. }}{ }_{\text {nom. }}$ and the unchanged temperature graph of the heating system. At the second stage, the dependence of the line installation efficiency on the AHP heat conversion factor at the nominal heat load was analyzed.

The initial data for the research are presented in [6].

The design scheme of a two-stage line installation with AHP is shown in Figure 1.

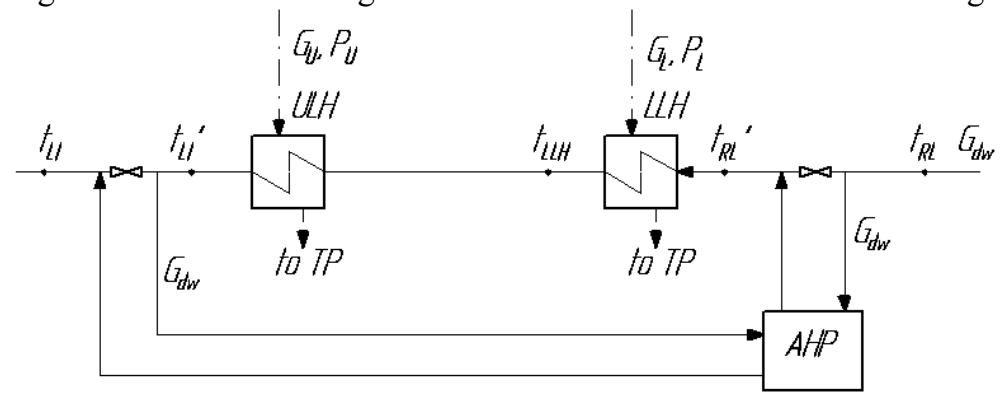

Fig. 1. The design scheme of a two-stage line installation with the AHP included in the scheme (ULH - upper line heater; LLH - lower line heater; TP - turbine plant; $\mathrm{G}_{\mathrm{dw}}$ - delivery water discharge; $\mathrm{G}_{\mathrm{U}}-$ vapor feed rate of selection on upper line heater; $\mathrm{P}_{\mathrm{U}}$ - vapor pressure of selection on upper line heater; $\mathrm{G}_{\mathrm{L}}$ - vapor feed rate of selection on lower line heater; $\mathrm{P}_{\mathrm{L}}$ - vapor pressure of selection on lower line heater; $t_{R L}$ - return line temperature; $t_{L L H}$ - delivery water temperature after the lower line heater; $t_{L I}-$ delivery water temperature after the line installation).

\section{Calculation results}

\subsection{The efficiency of a line installation using AHP with a change in the heat load}

The calculation results of the efficiency of a two-stage line installation with an AHP in comparison with the initial scheme at a minimum (design) outdoor air temperature and various heat loads are shown in Figures 2, 3.

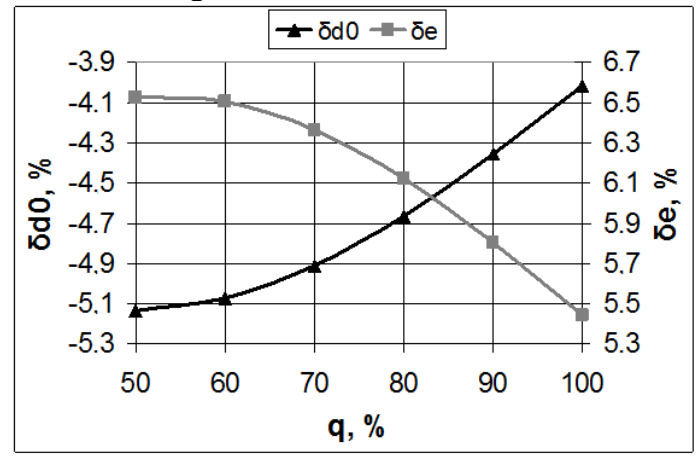

Fig. 2. The dependence of the relative change in the specific steam consumption for the turbine $\delta \mathrm{d}_{0}$ and the relative change in the specific electricity generation at heating consumption $\delta \mathrm{e}$ from the heat load of the line installation with the inclusion of the absorption heat pump into the two-stage heating of the delivery water at $\mathrm{t}_{\text {out.tem. }} \mathrm{d}$. 


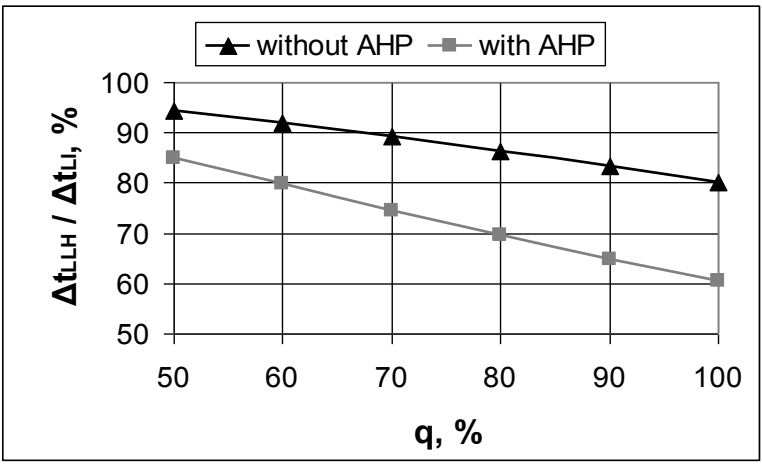

Fig. 3. The dependence of the proportion of the delivery water heating in the lower line heater from the heat load of the line installation in the original version and with the absorption heat pump in the scheme of the two-stage delivery water heating at $\mathrm{t}_{\text {out.tem. }}$.

\subsection{The efficiency of a line installation with an AHP with a change in the heat conversion factor}

The results of calculating the efficiency of a two-stage line installation with an AHP in comparison with a line installation without AHP at a minimum (design) outdoor air temperature and various AHP heat conversion factors are presented in Figures 4, 5.

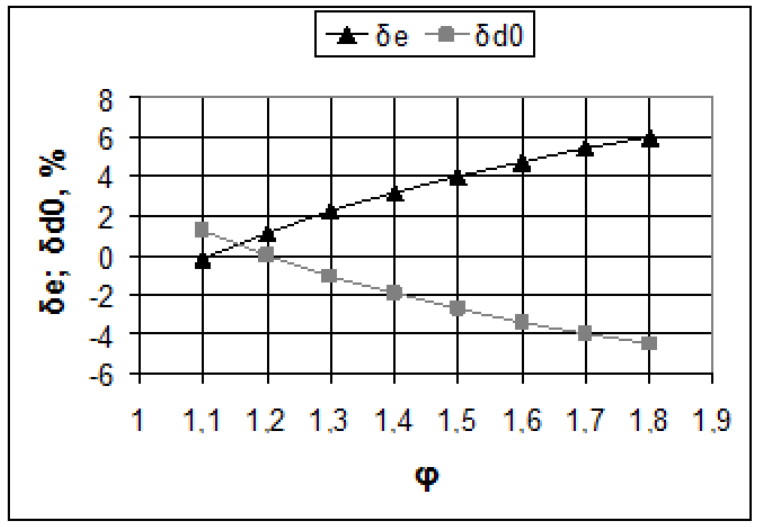

Fig. 4. The dependence of the relative change in the specific electricity generation at heating consumption $\delta \mathrm{e}$ and the specific steam consumption for the turbine $\delta \mathrm{d}_{0}$ on the AHP heat conversion factor when it is included in the two-stage delivery water heating scheme at $t_{\text {out.tem. }}$. . 


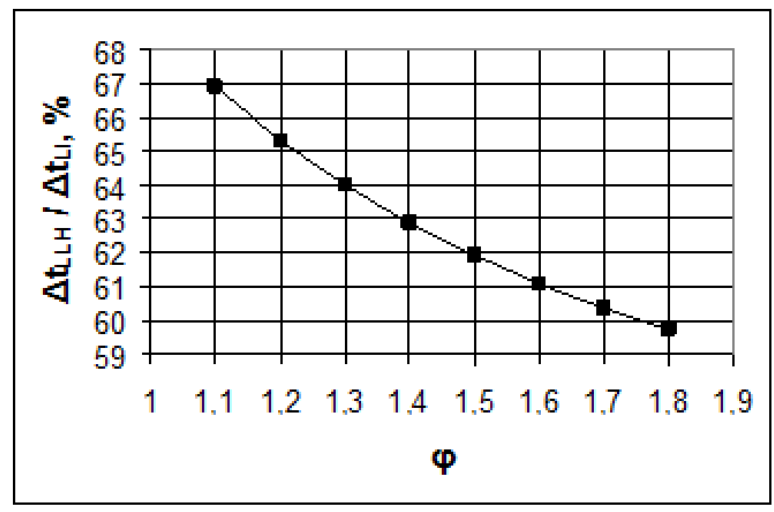

Fig. 5. The dependence of the delivery water heating proportion in the lower network heater on the heat conversion factor of the heat pump when it is included in the scheme of two-stage delivery water heating and the operation of the line installation according to the temperature schedule of the minimum design temperature of the outside air $\mathrm{t}_{\text {out.tem. }} \mathrm{d}$.

\section{Conclusions}

1. The use of AHP for equalizing the delivery water heating in the two-stage line installation of the extraction turbine while working in the heating mode leads to the maximum increase in the indicators of heating efficiency in the operating mode at the minimum design temperature of the outside air.

2. The efficiency of the absorption heat pump inclusion in the scheme of a two-stage line installation of a STP for equalizing the delivery water heating at the minimum design temperature of the outside air depends significantly on the heat load of the heat exchangers and the AHP heat conversion factor.

3. The economic effect of using AHP increases with a decrease in the heat load of the line installation (the parameters of the heating system do not change). With a heat decrease from the nominal value of up to $50 \%$ for the turbine $\mathrm{T}-110-130$, the decrease in the specific steam consumption for the turbine varies from $4 \%$ to $5.1 \%$, and the increase in the specific heat production by heating consumption varies from 5.4 to $6.5 \%$ compared with the corresponding operating modes of the turbine without AHP.

4. The analysis of the influence of the AHP heat conversion factor $\varphi$ on the efficiency of step heating at the nominal heat load of the extractions and the minimum design temperature of the outside air shows that an increase in the heating efficiency of the T110-130 turbine unit is achieved at values greater than 1.15. The use of AHP with values $\varphi=1,8$ allows to increase the electricity generation by heating consumption to $6 \%$ and to reduce the steam consumption for the turbine to $4.5 \%$ in comparison with the initial scheme.

5. The effect of reducing the specific steam consumption for the turbine and increasing the specific heat production by thermal absorption when introducing absorption heat pumps into the two-stage line installation is achieved by equalizing the heating of the delivery water in the line heaters. When the heat load of the line installation is reduced from 100 to $50 \%$, the decrease in the proportion of heating of the delivery water in the lower line heater, due to the input of the AHP with the heat conversion factor $\varphi=1.7$, changes from 19 to $9 \%$. At the nominal heat load of the line installation, the increase in the AHP heat conversion factor from 1.1 to 1.8 leads to a change in the proportion of the delivery water heating in the lower line heater from 67 to $60 \%$. 


\section{References}

1. D.P. Elizarov, E.I. Tazhiyev, Electric stations, 2 (1994) [in Russian]

2. A. L. Buran, V. E. Kozlov \& V. E. Filyukov, MATEC Web Conf. 110 (2017)

3. A. Gabdullina, N. Galashov, S. Tsibulskiy, I. Asanov, A. Kiselev, MATEC Web Conf. 91, 01004 (2016)

4. O.Yu.Romashova, O.R. Gabidullin, Energetics: Ecology, reliability, safety, 9, 239 (2003) [in Russian]

5. O.Yu.Romashova, O.R. Gabidullin, Energetics: Ecology, reliability, safety, 9, 222 (2004) [in Russian]

6. O.Yu. Romashova, D.S. Luzhkovoj, A.A. Tubolev, M.A. Vagner, MATEC Web Conf. 110 (2017) 